\title{
Fire Testing a New Fluorine-free AFFF Based on a Novel Class of Environmentally Sound High Performance Siloxane Surfactants
}

\author{
RALF HELMUT HETZER ${ }^{1}$, FELIX KÜMMERLEN ${ }^{1}$, KAI WIRZ ${ }^{2}$, DIRK BLUNK ${ }^{2}$ \\ ${ }^{1}$ Bundeswehr Research Institute for Protective Technologies and NBC-Protection (WIS) \\ Humboldtstr. 100, 29633 Munster, Germany. \\ ${ }^{2}$ Institute of Organic Chemistry, University of Cologne \\ Greinstr. 4, 50939 Köln, Germany.
}

\begin{abstract}
The most effective fire extinguishing agents for pool fires are Aqueous Film Forming Foams (AFFF). Today, all available AFFF contain polyfluorinated compounds (PFC), i.e. polyfluorinated tensides (PFT), to establish the aqueous film on the surface of a burning liquid. These fluorinated compounds are persistent, potentially bio-accumulative and toxic. Therefore it is essential to find environmentally sound substitutes for these problematic surfactants. Commercially available fluorine-free foams (FfreeF) lack the ability of aqueous film formation. Although FfreeF are performing well in many situations [1,2], there are numerous scenarios where an aqueous film forming component is mandatory for fast fire extinguishing, e.g. in case of burning liquids. To achieve a well performing AFFF, a new approach is to replace the film forming PFC/PFT by siloxane surfactants. Today, siloxane surfactants are typically used in plant protective agents, in textile surface treatment and as lubricants. As the properties of commercially available siloxane surfactants are not suitable for AFFF, new siloxane surfactants were designed, synthesized and tested for their suitability as film forming ingredients in AFFF formulations. The surface activity and foaming behaviour of model formulations have been determined. Finally, one experimentally fluorine-free AFFF formulation has been subjected to fire tests. In this context a new fire test for scarcely available chemicals is presented.
\end{abstract}

KEYWORDS: fire fighting foams, AFFF, A3F, class B foam, surfactants, fluorine-free, PFC, PFT

\section{INTRODUCTION}

Armed forces have to handle large amounts of different flammable liquids for their mission fulfillment. For this reason and because of their special threat situation they need the most effective extinguishing agents to fight extensive pool fires, which are, as it is generally accepted, Aqueous Film Forming Foams (AFFF). Responsible for the outstanding performance of AFFF is the eponymous water film which is established by this kind of foams on the surface of the burning liquid. The performance of fire extinguishing foams is improved in several ways by the aqueous film and hence by the property determining surfactant: The water film, which is located between the fuel and the foam, cools the surface of the fuel, acts as a vapor barrier, supports the spreading of the foam on the fuel and promotes the self-healing of the foam blanket after injuries. Because of these unique properties, AFFF is one of the most valuable tools in fighting hydrocarbon fuel fires.

The sole but severe disadvantage of existing AFFF is that the formation of the water film is exclusively provided by polyfluorinated surfactants. These polyfluorinated compounds (PFC) possess a complex environmentally harmful behavior [3] which led to serious restrictions and regulations with regard to the use of AFFF today. The best known example of this class of compounds is the surfactant Perfluorooctylsulfonate (PFOS) which was widely used in AFFF until 2005. Since 2006 PFOS is banned in the European Union [4] due to its persistency, toxicity and bioaccumulation and since 2009 PFOS has internationally been classified as persistent organic pollutant (POP) by inclusion into the Stockholm Convention [5]. After that, PFOS has been substituted in AFFF by other, but still polyfluorinated chemicals which are also not acceptable because also their polyfluorinated parts cannot be degraded in the environment. Furthermore, their toxicology and their environmental behaviors are not completely clarified, yet. Because of the environmentally and toxicological problems AFFF-containing extinguishing water must be surely collected and disposed at high cost in each case of application, since otherwise there is a high probability to source an enduring contamination of soil and ground water with PFC.

As a consequence of this problematic environmental behavior of the classical AFFF, the Bundeswehr Research Institute for Protective - Technologies and NBC-Protection (WIS) in collaboration with the Institute of Organic Chemistry of the University of Cologne have been researching on fluorine-free AFFF since 2010 
$[6,7]$. The aim of the research project is the design of an utmost environmentally friendly and non-toxic AFFF for military fuels without any persistent components [8].

\section{THEORETICAL BACKGROUND}

The water film of AFFF spreads spontaneously on the surface of a liquid fuel. For this spreading process a positive spreading coefficient $(S)$ is required, which is defined as the difference between the surface tension of the fuel $\left(\delta_{F}\right)$ and the sum of the surface tension of the aqueous phase (the extinguishing agent) $\left(\delta_{A}\right)$ and the interfacial tension between the fuel and the aqueous phase $\left(\delta_{I}\right)$ (Formula 1) [9]. A spontaneous formation of the water film is physically possible only if $S$ is positive.

Formula 1: Definition of the spreading coefficient $(S)$.

$S=\delta_{F}-\left(\delta_{A}+\delta_{I}\right)$

The primary indicator of success for the new extinguishing agent is defined by our mission: The aim is to design a fluorine-free AFFF for military relevant fuels, i.e. the NATO standard fuel F-34. For simplification of the logistics during missions [10] the Single Fuel Concept of the NATO stipulates that the exclusively stocked and used fuel is F-34 which shows a surface tension of $\delta_{F}$ of $25.8 \mathrm{mN} / \mathrm{m}$ at room temperature (see Table 1). Subtracting an additional safety margin gives a target value of $\delta_{F}=25.0 \mathrm{mN} / \mathrm{m}$, which should be the upper limit for the sum of $\delta_{A}+\delta_{I}$ for the planned fluorine-free AFFF. Fortunately, the civilian alternative fuels for F-34, Diesel or Jet A1, which are also partially used by the Armed Forces, show a $\delta_{F}-$ value of $\geq 25.0 \mathrm{mN} / \mathrm{m}$ (see Table 1). Therefore, a newly designed fluorine-free AFFF which functions on F-34 should also build a water film on these fuels, too. But it has to be mentioned that through the restriction of $\delta_{F} \geq 25.0 \mathrm{mN} / \mathrm{m}$ gasoline, the most frequently used fuel in the civilian sector, is not included in this primary aim (see Table 1). On the other hand, the milestone of $\delta_{F} \geq 25.0 \mathrm{mN} / \mathrm{m}$ represents only the minimum goal of our research based on the requirements discussed above: surpassing this value is quite possible, even if it is not the primary objective. In any case, a fluorine-free and biologically degradable AFFF based on $\delta_{F} \geq 25.0 \mathrm{mN} / \mathrm{m}$ is also interesting for many other civilian applications, because important flammable liquids like crude oil, diesel, biodiesel (FAME) or meltable plastics are still covered by this target $\delta_{F}$.

Table 1: Surface tensions of various fuels.

\begin{tabular}{|c|c|c|}
\hline Fuel or Liquid & Surface Tension $\left(\delta_{F}\right)[\mathbf{m N} / \mathbf{m}]$ & Temperature $\left[^{\circ} \mathbf{C}\right]$ \\
\hline Military relevant fuels: & & 23 \\
F-34 (JP 8) & 25.8 & 24 \\
Jet A1 $^{\mathrm{a}}$ & 26.7 & 24 \\
Diesel $^{\mathrm{a}}$ & 28.3 & 24 \\
\hline Reference liquid: $^{\text {Cyclohexane (p.a.) }}$ & 24.9 & 24 \\
\hline Other important liquids: $^{\mathrm{a}}$ & & 24 \\
Gasoline $^{\mathrm{a}}$ & 20.8 & 24 \\
Crude Oil $^{\mathrm{a}}$ & 28.5 & 24 \\
FAME (Bio-Diesel) $^{\mathrm{a}}$ & 31.5 & 24 \\
\hline
\end{tabular}

a: These fluid samples were kindly provided by Mr. Wekenborg, BP Refinery Emsland, Germany.

Due to the necessity of a positive spreading coefficient $S$ the sum of the surface tension $\delta_{A}$ and interfacial tension $\delta_{I}$ of the spreading solution must be significantly lower than $25.0 \mathrm{mN} / \mathrm{m}$. Therefore the surface tension of the water draining out of the foam must be extremely reduced by high performance surfactants (see Table 2). The only currently known surfactants which are able to perform such a sufficiently large decrease of the surface tension of an aqueous solution are siloxane derivatives and the undesired polyfluorinated surfactants. Since polyfluorinated surfactants are banned due to the above-mentioned environmental problems, siloxane 
surfactants have been identified as the most promising class of surfactants for fluorine-free AFFF and selected as our research focus. From experience, siloxane surfactants provide a spreading coefficient $S$ of about 5 $\mathrm{mN} / \mathrm{m}$ (see Table 2). Typical values for $\delta_{I}$ are between approximately 0 and $5 \mathrm{mN} / \mathrm{m}$ in the case of siloxane surfactants.

Table 2: Minimum surface tensions and estimated spreading coefficients of aqueous surfactant solutions at room temperature.

\begin{tabular}{|c|c|c|c|}
\hline Surfactant Type & $\begin{array}{c}\text { Minimum Surface } \\
\text { Tension }\left(\boldsymbol{\delta}_{\boldsymbol{A}}\right)\end{array}$ & $\begin{array}{c}\text { Spreading Coefficient on } \\
\text { Cyclohexane }(\boldsymbol{S})^{\mathbf{b}}\end{array}$ & Suitability for AFFF \\
\hline $\begin{array}{c}\text { Polyfluorinated } \\
\text { Surfactants }\end{array}$ & $15 \mathrm{mN} / \mathrm{m}$ & $+10 \mathrm{mN} / \mathrm{m}$ & Yes \\
\hline $\begin{array}{c}\text { Siloxane } \\
\text { Surfactants }\end{array}$ & $20 \mathrm{mN} / \mathrm{m}$ & $+5 \mathrm{mN} / \mathrm{m}$ & Probably \\
\hline Alkyl Surfactants & $28 \mathrm{mN} / \mathrm{m}$ & $-3 \mathrm{mN} / \mathrm{m}$ & No \\
\hline Pure Water & $73 \mathrm{mN} / \mathrm{m}$ & $-48 \mathrm{mN} / \mathrm{m}$ & No \\
\hline
\end{tabular}

: The values for $S$ are calculated without consideration of the contribute $\delta_{I}$.

The biological impact of siloxane surfactants should be significantly lower than the effect of the PFC because the hydrophobic part of the siloxane surfactants does not contain the extremely stable and not bio-degradable carbon-fluorine bonds. In siloxane surfactants the eponymous siloxane group forms the hydrophobic part of the surfactant. This group mainly contains silicon-methyl and silicone-oxygen bonds. Compounds of this type degrade in nature. It is well known that the silicon-oxygen bonds can be cleaved by water and the degradation of the accruing hydrolysis products is reported for microorganisms. [11]

\section{EXPERIMENTAL}

\section{Materials and Methods}

Cyclohexane (BCD GmbH, purity $\geq 99.7 \%, \delta_{\mathrm{F}}=24.9 \mathrm{mN} / \mathrm{m}$, flash point $-20{ }^{\circ} \mathrm{C}$ ) was distilled once and used as reference liquid. Its defined composition (single compound), appropriate surface tension and low flash point support meaningful and reproducible spreading and vapor tightness tests.

F-34 was obtained out of the common military supply and used as received without any further treatment.

A variety of commercial siloxane tensides, the classical PFC containing AFFF and the conventional Class B foam were used as delivered from the supplier and according to the given conditions.

The new siloxane surfactants have been prepared as described in references [6] and [7].

Surface tension and interfacial tension measurements were performed with a Krüss K100 MK2 Tensiometer equipped with a Wilhelmy-Plate (Krüss GmbH, Hamburg; Germany).

Film formation tests were performed in a petri dish filled with a $3 \mathrm{~mm}$ layer of the respective organic liquid, i.e. cyclohexane or F-34. A drop of the pre-prepared respective surfactant solution was supported onto the liquid's surface and the expansion of the water film was observed optically. In order to have direct access to the water film, the surfactant solutions were not foamed in these experiments.

The vapor tightness of the films was checked with a small test flame after the film formation. For this purpose the test flame was slowly approached to a distance of $5 \mathrm{~mm}$ above the fuel surface in the middle of the petri dish. The cyclohexane ignited if no water film was formed on the surface or if it was not sufficiently vapor tight. As in the film formation tests, the surfactant solutions were not foamed in these experiments.

Fire tests were conducted in a round $0.66 \mathrm{~m}^{2}$-fire test pan made of stainless steel which was filled with a 3.0 $\mathrm{cm}$ water buffer and 10.0 1 F-34 as fuel. As foaming device a Low Expansion Nozzle from the Micro Foam Unit (Jürgen Arens, Production and Distribution of Instructional Media, Cologne, Germany) was used with a discharge rate of $1.0 \mathrm{~kg} / \mathrm{min}$ and a working pressure of $4.5 \mathrm{bar}$, which corresponds to an application rate of 1.5 
$\mathrm{kg} /\left(\min \times \mathrm{m}^{2}\right)$ for the fire test pan mentioned above. The foam solution was supplied from a pressurized $25-\mathrm{L}$ reservoir (M. F. U. V-25, also Jürgen Arens) which was kept at a constant pressure throughout the foam application by a connected compressed air bottle with pressure reducer.

Drainage times have been measured in graduated glass cylinders which were filled with foam produced with the same setup as in the fire tests.

\section{Water Film Formation on Cyclohexane or F-34}

\section{Commercially Available Siloxane Surfactants}

A series of solutions from commercially available siloxane surfactants were tested with regard to their spreading behavior on cyclohexane and F-34. The chemical structures of these surfactants based mainly on siloxanes connected to oligo ethylene glycol ethers as hydrophilic group.

In addition to the spreading experiments, $\delta_{A}$ and $\delta_{I}$ of the surfactant solutions were measured and the resulting spreading coefficients $S$ calculated, cf. Table 3 .

Surprisingly the aqueous solutions of commercial siloxane surfactants were not able to form a water film on cyclohexane or F-34, despite the fact that in many cases positive spreading coefficients were calculated from the measured $\delta_{A}$ and $\delta_{I}$. Apparently, a positive spreading coefficient $(S>0)$ is thus only a necessary but not a sufficient requirement for the water film formation [12].

Even the addition of a supplementary conventional surfactant, i.e. an alkyl glycoside, which usually smoothens the film formation, did not change the spreading behavior of the aqueous solutions of commercially available siloxane surfactants. Also in these cases no film formation was observable.

\section{New Siloxane Surfactants}

Since the well-established siloxane derivatives discussed above turned out to be unsuitable for AFFF purposes, numerous new siloxane surfactants with pioneering chemical structures, differing in their hydrophilic groups or in their siloxane moiety, were synthesized and tested by the University of Cologne and WIS in order to identify such examples that promote the spreading on cyclohexane or F-34.

Most of the novel siloxane surfactants carry a carbohydrate as the hydrophilic part and none of them contains halogenides (as e.g. fluorine) in their chemical structure. In this respect the new foaming agents should be environmentally sound and promote a sustainable chemistry of the AFFF. Further information is provided in our current patent application [6,7].

For most of the new siloxane derivatives, measurements of the minimal surface tension and interfacial tension with cyclohexane confirmed that they might be suitable as film forming component in fluorine-free AFFF (cf. Table 3). And indeed, several new siloxane surfactants could be identified that actually enable the spreading of the aqueous surfactant solutions and form a water film on top of the organic liquid (cyclohexane or fuel) as it is demanded for an AFFF.

With aqueous solutions of the pure siloxane surfactants of the new type, water film formation on top of cyclohexane or F-34 was clearly observable. The addition of the supplementary conventional surfactant (alkyl glycoside) promoted this process, the film tightness and the foamability of the solutions.

As expected and as can be seen from Table 3, solutions of the supplementary conventional surfactant alone are not able to form an aqueous film on the surface of the apolar organic liquids, which indicates that the new siloxane surfactants are a mandatory component of the new fluorine free AFFF compositions. 
Table 3: Comparison of the spreading coefficients of different aqueous surfactant solutions. The data given in the table refer to a typical representative for each surfactant class.

\begin{tabular}{|c|c|c|c|c|c|}
\hline No & Composition & $\begin{array}{c}\boldsymbol{\delta}_{A} \\
{[\mathbf{m N} / \mathbf{m}]}\end{array}$ & $\begin{array}{c}\delta_{I} \\
{[\mathrm{mN} / \mathrm{m}]}\end{array}$ & $\underset{[\mathrm{mN} / \mathrm{m}]}{S}$ & $\begin{array}{c}\text { Water Film } \\
\text { Formation on } \\
\text { Cyclohexane or } \\
\text { F-34 }\end{array}$ \\
\hline 1 & Commercial Siloxane Surfactant $(1.0 \mathrm{~g} / \mathrm{l})$ & 20.6 & 0.5 & 3.9 & No \\
\hline 2 & $\begin{array}{c}\text { Commercial Siloxane Surfactant }(1.0 \mathrm{~g} / \mathrm{l}) \\
\text { Alkyl Glycoside }(4.5 \mathrm{~g} / \mathrm{l})\end{array}$ & 23.9 & 1.5 & -0.4 & No \\
\hline 3 & New Siloxane Surfactant $(1.0 \mathrm{~g} / \mathrm{l})$ & 20.2 & 0.5 & 4.3 & Yes \\
\hline 4 & $\begin{array}{c}\text { New Siloxane Surfactant }(1.0 \mathrm{~g} / \mathrm{l}) \\
\text { Alkyl Glycoside }(4.5 \mathrm{~g} / \mathrm{l})\end{array}$ & 22.9 & 0.6 & 1.5 & Yes \\
\hline 5 & Alkyl Glycoside $(4.5 \mathrm{~g} / \mathrm{l})$ & 28.4 & 1.5 & -4.9 & No \\
\hline
\end{tabular}

\section{Foamability and Drainage Time}

For the fire tests described below, the best rated (with respect to the water film formation) premixed solution of the new siloxane surfactants was used (cf. Table 3, No. 4 and Table 4, No. 1). This experimental foam solution was prepared by mixing a film forming siloxane (Table 3, No. 3) with a commercially available alkyl glycoside surfactant (Table 3, No. 5) as foaming agent. The concentration of the auxiliary foaming agent was adjusted by the expansion in such a way that the experimental solution reaches nearly identical expansion values as the tested commercial firefighting foams (cf. Table 4): all expansion values range between 9.3 and 10.4 and are thus comparable.

Table 4: Comparison of various foaming solutions and commercial firefighting foams according to $50 \%$ drainage time and expansion.

\begin{tabular}{|c|c|c|c|c|c|c|}
\hline No & Type & Composition & $\begin{array}{c}\text { PFC } \\
\text { Content }\end{array}$ & $\begin{array}{l}\text { Water Film } \\
\text { Formation }\end{array}$ & Expansion & $\begin{array}{c}\mathbf{5 0 \% -} \\
\text { Drainage } \\
\text { Time } \\
\text { [min] }\end{array}$ \\
\hline 1 & $\begin{array}{c}\text { New } \\
\text { Siloxane } \\
\text { Surfactant }\end{array}$ & $\begin{array}{l}\text { Siloxane Surfactant }(1.0 \mathrm{~g} / \mathrm{l}) \\
\text { Alkyl Glycoside }(4.5 \mathrm{~g} / 1)\end{array}$ & PFC free & Yes & 9.4 & 3.2 \\
\hline 2 & $\begin{array}{c}\text { Blank } \\
\text { Sample }\end{array}$ & Alkyl Glycoside (4.5 g/l) & PFC free & No & 10.0 & 3.3 \\
\hline 3 & \multirow{2}{*}{ AFFF } & $3.0 \%$ Solution & $\begin{array}{c}\text { PFC } \\
\text { containing }\end{array}$ & Yes & 9.9 & 7.9 \\
\hline 4 & & $3.0 \%$ Solution & $\begin{array}{c}\text { PFC } \\
\text { containing }\end{array}$ & Yes & 10.4 & 7.4 \\
\hline 5 & \multirow{3}{*}{$\begin{array}{l}\text { Class B- } \\
\text { Foam }\end{array}$} & $3.0 \%$ Solution & PFC free & No & 9.3 & 15.9 \\
\hline 6 & & $3.0 \%$ Solution & PFC free & No & 9.3 & 16.5 \\
\hline 7 & & $0.5 \%$ Solution & PFC free & No & 9.9 & 8.5 \\
\hline
\end{tabular}


The 50\%-drainage times listed in Table 4 show that the respective periods for the experimental siloxane surfactant solution and the blank sample are shorter than half the duration for the tested AFFF (3.2 min and $3.3 \mathrm{~min}$ vs. $7.9 \mathrm{~min}$ and $7.4 \mathrm{~min}$, respectively). The $50 \%$-drainage times of the fluorine-free class B foams (Table 4, No. 5, 6 and 7) were again significantly higher. The low 50\%-drainage times of the experimental foam solutions (Table 4, No. 1 and 2) can be explained by the missing foam stabilizers in the mixtures. These have not yet been added in this test series in order to maintain a simple system for the first trials. Their integration is planned for the next research step.

\section{Fire Tests}

The available amounts of the new carbohydrate siloxane surfactants are very limited, since these have only been synthesized in a laboratory scale, yet. Mainly for this reason the fire tests reported here were not conducted on the basis of international standards such as EN 1569 or ICAO. Rather, the fire tests were set up as outlined in the Materials and Methods section and as described in the following and in Figure 1. The foam was gently applied over a ramp $(0.54 \mathrm{~m}$ high, $1.65 \mathrm{~m}$ long, $0.15 \mathrm{~m}$ wide) onto the surface of the fuel with a very low application rate of $1.5 \mathrm{~kg} /\left(\mathrm{min} \times \mathrm{m}^{2}\right)$. This procedure should avoid any pressure or directing effects but emphasize the effect of the water film and the high performance of AFFF during the extinguishing tests [13]. Moreover, we selected this experimental setup, because it allows a high degree of reproducibility.
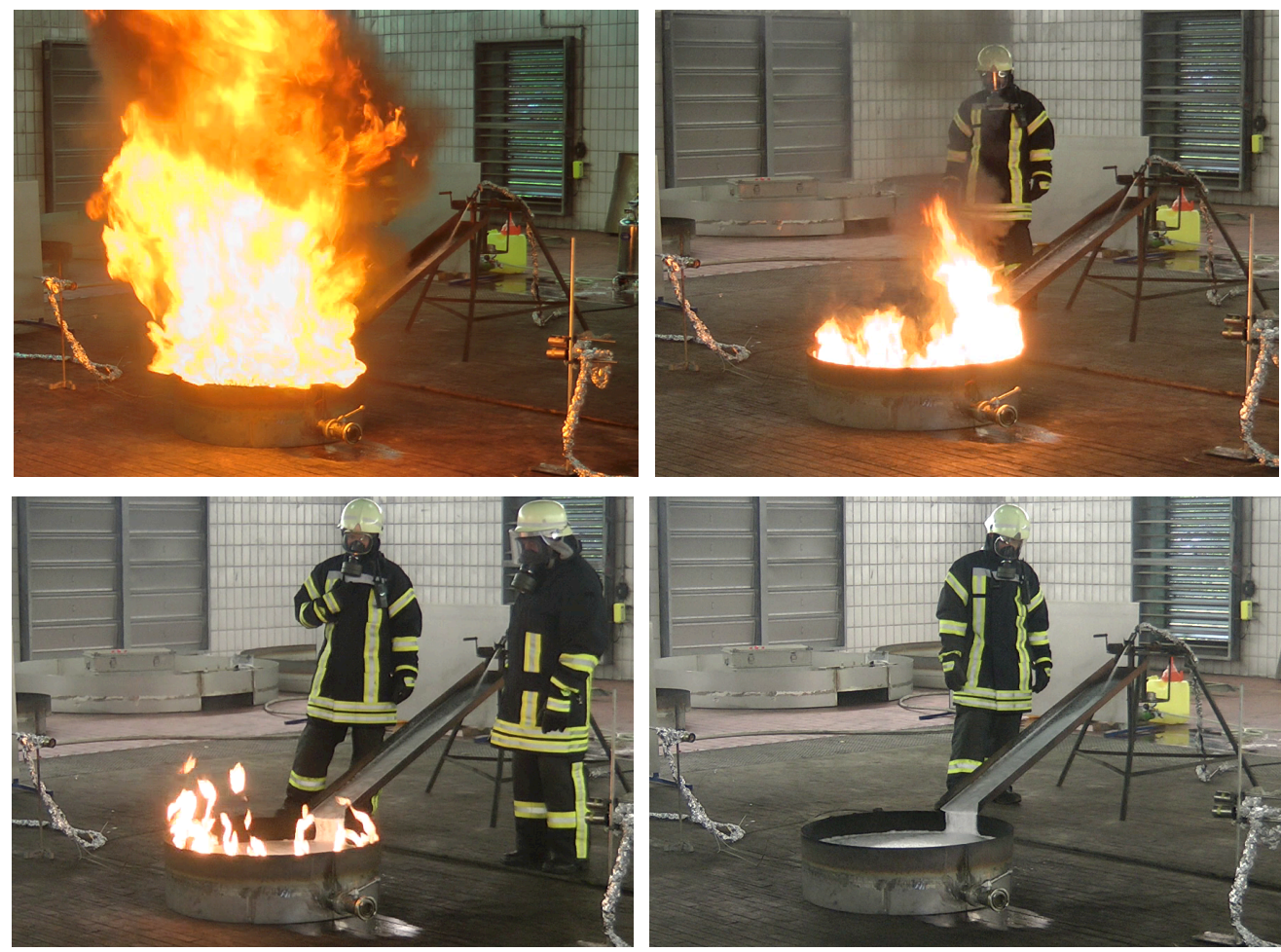

Fig. 1: Successful suppression experiment (Foam slide in the background; heat flux sensors on the left and right.).

To improve the reproducibility, each fire test was carried out in a sheltered fire house and performed according to the protocol described in the following. The experiments were recorded by water-cooled heat flux sensors with a sampling rate of $1 \mathrm{~Hz}$ (see Figure 2). Individual events, such as the start of the foam application or the extinction of the last flames, are recorded by button generated signals. After the burning of the complete fuel surface has been reached, a pre-burn time of 60 seconds was awaited before the foam application was started. After the extinction of the last flames (100\%-control time) the foam flow is continued for another $60 \mathrm{~s}$. A successful extinguishing test is followed by a burn back test: After another $60 \mathrm{~s}$ break, a burn back pot is positioned centrally in the fire pan and ignited. The round burn back pot has a height of $10.0 \mathrm{~cm}$ and a radius of $5.8 \mathrm{~cm}$ and is filled up to a height of $8.0 \mathrm{~cm}$ with technical heptane as fuel. 
In order to assess the results of this method the tests were repeated with several of commercial fluorine-free Class B foam agents and fluorine-containing AFFF based on the German Military Standard (TL 4210-0112) [9].

As could be expected from the spreading coefficients (cf. Table 2) and the product development status, the fluorine-containing commercial AFFF performs best in the fire extinguishing test (Table 5, No. 3 and 4 and Figure 3), and in particular significantly better than the commercially available fluorine-free Class B foams (Table 5, No. 5, 6 and 7).

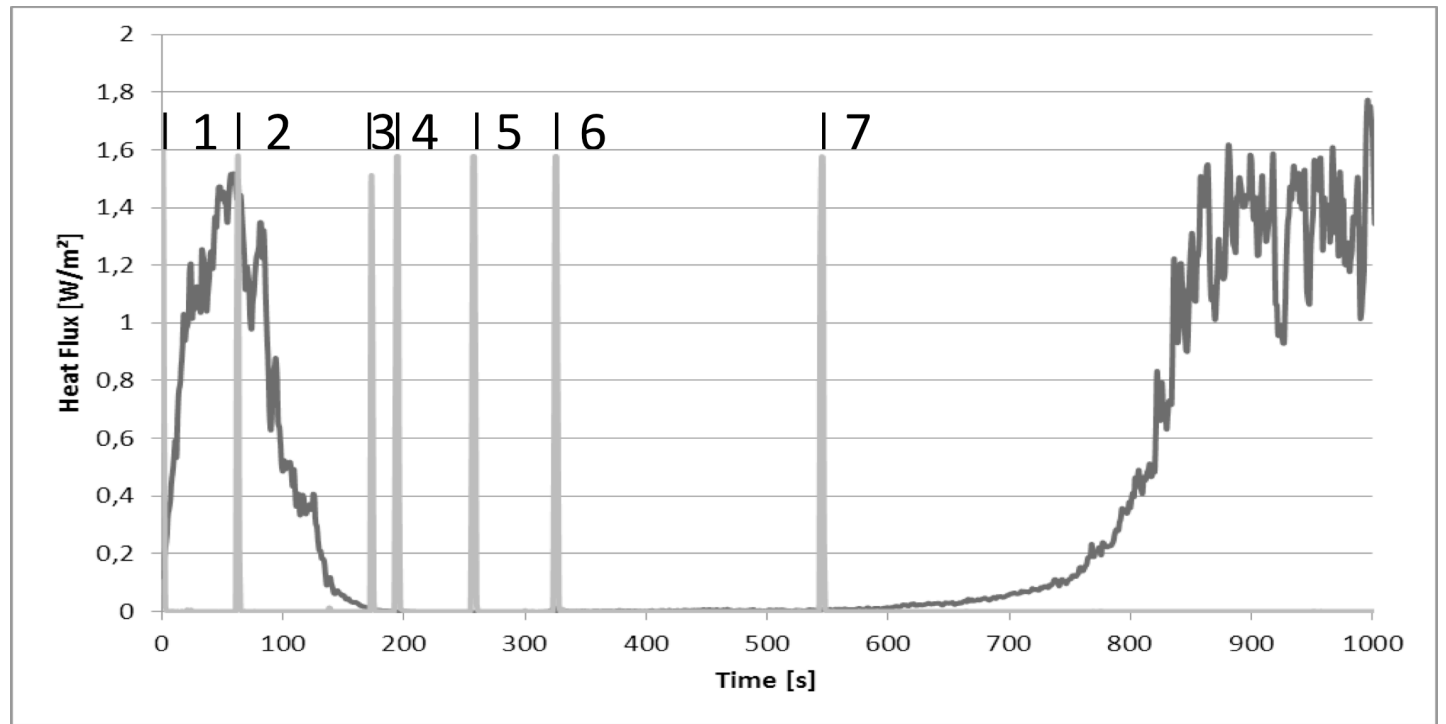

Fig. 2: Heat flux during a fire and subsequent burn back test with manually marked event peaks (1: Burning of the complete fuel surface; 2 : End of the preburn time and start of the foam application; 3: 99\%-Control; 4 : 100\%-Control; 5: End of the foam application; 6: Start of the burn back experiment; 7: First flames outside of the burn back pot.).

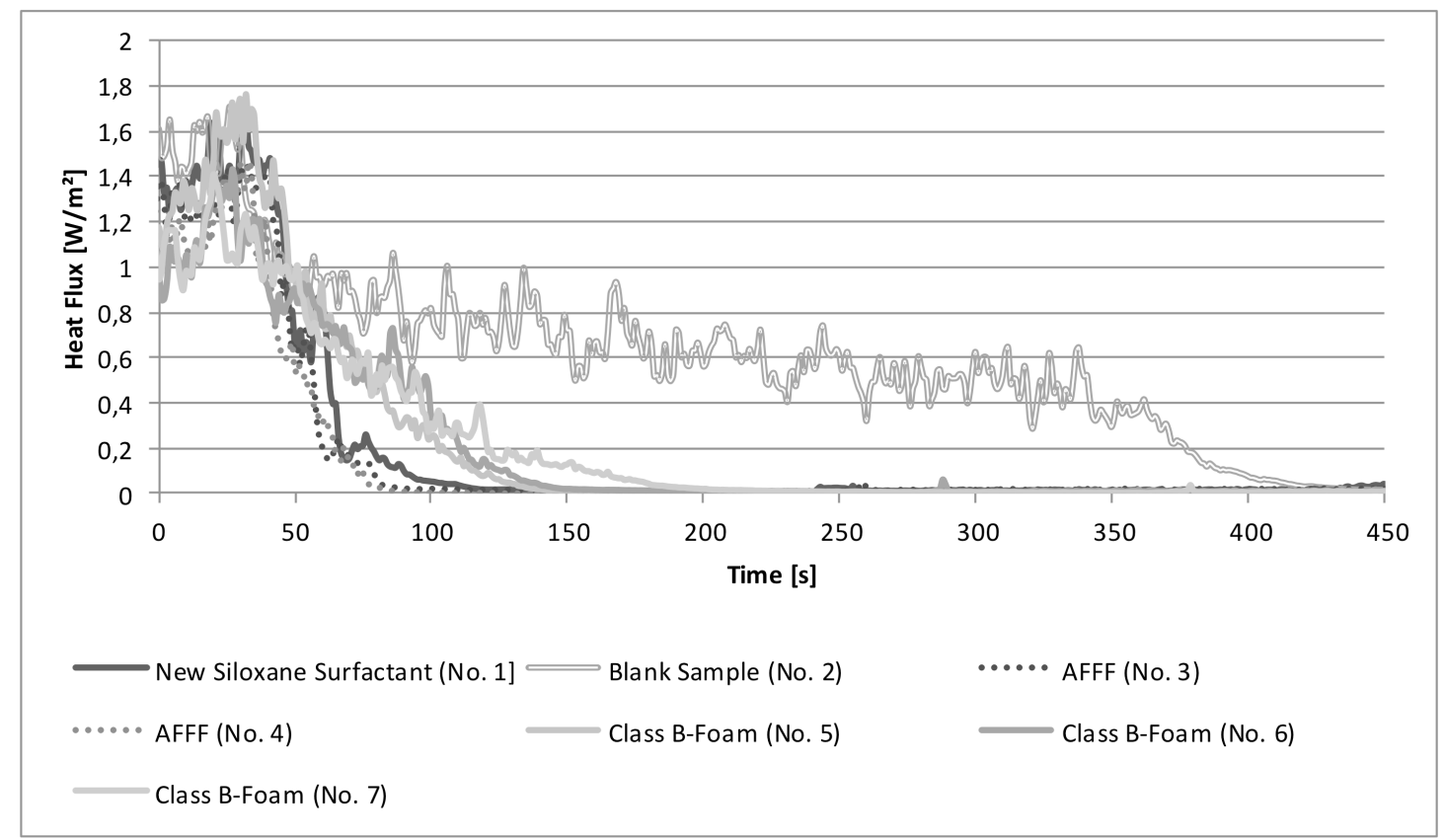

Fig. 3: Comparison of heat flux during the extinguishing process of the siloxane-based foam (No. 1) with commercial foams (AFFF: No. 3 and 4, non-AFFF Class B: No. 5 and 6) and an alkyl glycoside foam (blank sample, No. 2). The diagram starts with the beginning of the foam application. 
But remarkably, the novel fluorine-free aqueous film forming foam (Table 5, No. 1) has only a slightly less good performance than the polluting commercial AFFF, and performs already much better than the commercial fluorine-free class-B alternatives. This compelling result was obtained although the experimental film forming foam is a very simple, non-optimized mixture of a film forming surfactant and a foam forming surfactant and not yet an elaborated product. The experimental mixture is completely lacking any foam stabilizers or other common ingredients. Of course this simplicity is also reflected in the low 50\%-drainage time (cf. Table 4) and an optimal result could not be expected in this early stage of the research. But the extinguishing performance of the experimental siloxane based AFFF is already by now superior to the commercially available fluorine-free fire extinguishing foams. This good performance is due to the water film which could form solely because of the presence of the siloxane surfactant. This assumption is confirmed by the experimental results of the blank sample (Table 5, No. 2) which had the same composition as the experimental siloxane solution with the only difference that the film forming siloxane surfactant was lacking. This small difference led to a massive increase of the extinguishing times despite the otherwise identical foam characteristics listed in Table 4. Since the ability to form a water film on top of F-34 is the only difference between both foam solutions, this must be the reason for their dissimilar extinguishing times.

Table 5: Comparison of the experimental extinguishing times of the siloxane-based foam with commercial foams.

\begin{tabular}{|c|c|c|c|c|c|c|c|}
\hline No & Type & Composition & $\begin{array}{c}\text { PFC } \\
\text { Content }\end{array}$ & $\begin{array}{c}\text { Water } \\
\text { Film } \\
\text { Formation }\end{array}$ & $\begin{array}{c}\text { 99\%- } \\
\text { Control- } \\
\text { Time [s] }\end{array}$ & $\begin{array}{l}100 \%- \\
\text { Control- } \\
\text { Time [s] }\end{array}$ & $\begin{array}{c}\text { 25\%-Burn } \\
\text { Back } \\
\text { Time [s] }\end{array}$ \\
\hline 1 & $\begin{array}{c}\text { New } \\
\text { Siloxane } \\
\text { Surfactant }\end{array}$ & $\begin{array}{c}\text { Siloxane Surfactant } \\
(1.0 \mathrm{~g} / \mathrm{l}), \text { Alkyl } \\
\text { Glycoside }(4.5 \mathrm{~g} / \mathrm{l})\end{array}$ & PFC free & Yes & 111 & 131 & 442 \\
\hline 2 & $\begin{array}{c}\text { Blank } \\
\text { Sample }\end{array}$ & $\begin{array}{l}\text { Alkyl Glycoside } \\
\text { (4.5 g/l) }\end{array}$ & PFC free & No & 477 & 536 & 164 \\
\hline 3 & \multirow{2}{*}{ AFFF } & $3.0 \%$ Solution & $\begin{array}{c}\text { PFC } \\
\text { containing }\end{array}$ & Yes & 81 & 136 & 745 \\
\hline 4 & & $3.0 \%$ Solution & $\begin{array}{c}\text { PFC } \\
\text { containing }\end{array}$ & Yes & 85 & 103 & 776 \\
\hline 5 & \multirow{3}{*}{$\begin{array}{c}\text { Class } \\
\text { B-Foam }\end{array}$} & $3.0 \%$ Solution & PFC free & No & 140 & 161 & 494 \\
\hline 6 & & $3.0 \%$ Solution & PFC free & No & 149 & 169 & 392 \\
\hline 7 & & $0.5 \%$ Solution & PFC free & No & 209 & 254 & 275 \\
\hline
\end{tabular}

The burn back times determined by heat flux also show the superiority of the commercial fluorine-containing AFFF to the other fire extinguishing agents (cf. Table 5). But still our experimental fluorine-free water film forming foam ranks at the same level as the best fluorine-free class-B foams. The $25 \%$-burn back time of the blank sample is about $63 \%$ shorter than that of the experimental siloxane surfactant solution. Again, this observation is a confirmation of the effectiveness of the water film because the film acts as a vapour barrier and reduces the speed of flame spreading during the back burn process. Additionally the water film diminishes the friction between foam and fuel so that the self-propagation of the foam is supported. These effects together cause the significantly improved back burn behaviour of the siloxane containing solution to the blank sample and the class B-foams (cf. Table 5).

Although being not in the initial aim of this study some preliminary tests of the new siloxane AFFF showed that they also show the water film formation with a good performance on civilian gasoline. However, these investigations are only in their very initial state and will be reported in a later stage. 


\section{CONCLUSIONS}

A new family of carbohydrate siloxane surfactants has been synthesized and successfully tested for its AFFF capabilities, i.e. to enable the spontaneous formation of a water film on top of a fuel (e.g. F-34 or cyclohexane). Since structurally different, commercial siloxane detergents were not able to perform the distinct properties of AFFF, the chemical nature of the hydrophilic group of the siloxane surfactants seems to be decisive for the spreading process. The new carbohydrate based siloxane surfactants are completely halogen free (fluorine free) and to the best of our knowledge environmentally sound.

For the new experimental foam solutions the spontaneous formation of a water film on cyclohexane as well as on F-34 was observed, which has to be attributed to the presence of the new carbohydrate siloxane surfactants. A comparison of commercial fire fighting foam agents with the experimental siloxane surfactant blend and blind tests proves that the water film significantly promotes the extinguishing performance in terms of extinction times and burn back process. It is particularly noticeable that the extinguishing performance of the experimental siloxane blend is only surpassed by the fluorine-containing AFFF although its composition is net yet optimized, whereas the fluorine-free Class B foams are clearly performing less good. For the future the drainage of the siloxane containing foam should be adjusted to the behaviour of the classical AFFF to optimize the burn back characteristics of the foam. After this, we will try to formulate a storage stable foam agent concentrate.

Due to the experimental results presented here it seems to be possible to produce a fluorine-free AFFF for the military relevant fuels based on siloxane surfactants. Preliminary but also promising results have been obtained for civilian gasoline, too. The extinguishing performance of classical PFC-containing AFFF is almost reached already at this early stage of the work. In our future work we aim to achieve a similarly excellent extinguishing performance and burn back resistance like the polluting fluorine-containing AFFF by improving the formulation of the experimental foam agent.

\section{REFERENCES}

[1] B. Williams, T. Murray, C. Butterworth, R. Sheinson, C. Whitehurst, J. Farley, J. Fleming, Extinguishment and Burnback Tests of Fluorinated and Fluorine-free Firefighting Foams With and Without Film Formation, Proceedings of the NFPA SUPDET 2011 conference, Phoenix, AZ, USA, 2012 (paper available at http://www.nfpa.org/assets/files//PDF/Proceedings/SUPDET11WilliamsPaper.pdf).

[2] T. H. Schaefer, B. Z. Dlugogorski, and E. M. Kennedy, Sealability Properties of Fluorine-Free FireFighting Foams (FfreeF), Fire Technol., 44, 297-309 (2008), DOI: 10.1007/s10694-007-0030-8.

[3] F. M. Hekster, R. W. P. M. Laane, P. de Voogt, Environmental and Toxicity Effects of Perfluoroalkylated Substances, Reviews of Environmental Contamination and Toxicology Volume 179, p. 99-121 (2003).

[4] European Parliament and Council (Ed.), Directive 2006/122/EC of the European Parliament and Council, 12.12.2006.

[5] UNEP, Stockholm Convention on Persistent Organic Pollutants - Annex B, United Nations (UN), 29.08.2009.

[6] D. Blunk, R. H. Hetzer, A. Sager-Wiedmann, K. Wirz, Siloxanhaltiger Löschschaum, DE102011053304.4, 2011.

[7] D. Blunk, R. H. Hetzer, A. Sager-Wiedmann, K. Wirz, Siloxane-containing fire extinguishing foam, PCT/EP2012/067109 (2012).

[8] R. H. Hetzer, D. Blunk, V. Hack, K. Wirz, Extinguishing Foams of the Future - Powerful and Environmentally Friendly, 2011 - Annual Military Scientific Research Report, Bundesministerium der Verteidigung, Bonn, Germany, 2012, p. 70-71.

[9] W. D. Harkins, A. Feldman, Films. The Spreading of Liquids and the Spreading Coefficient, Journal of the American Chemical Society, 44 (12), 2665-2685 (1922), DOI: 10.1021/ja01433a001.

[10] SNLC Secretariat, NATO Logistics Handbook, NATO HQ, Brussels, Belgium, 1997, p. 141. 
[11] G. Chandra, Review of the environmental fate and effects of silicone materials in textile applications, Textile Chemist and Colorist, 27 (4), 21-24 (1995).

[12] Ronald S. Sheinson, Bradley A. Williams, C. Green, J. W. Fleming, R. Anleitner, S. Ayers, A. Maranghides, The Future of Aqueous Film Forming Foam (AFFF): Performance Parameters and Requirements, Proceedings of the 12th Halon Options Technical Working Conference, Albuquerque, NM, USA, 2002 (paper available at http://www.nist.gov/el/fire_research/upload/R0201327.pdf).

[13] B. Z. Dlugogorski, C. Grimmond, E. M. Kennedy, Small Scale Test Protocol for Class B Foams, Halon Options Technical Working Conference, 16th Proceedings. HOTWC 2006. May 16-18, 2006, Albuquerque, NM, USA, p. 1-20, 2006 (paper available at http://www.fire.nist.gov/bfrlpubs/fire06/PDF/f06060.pdf). 